\title{
A giant spider from the Jurassic of China reveals greater diversity of the orbicularian stem group
}

\author{
Paul A. Selden • ChungKun Shih • Dong Ren
}

Received: 6 November 2013 /Revised: 12 November 2013 / Accepted: 14 November 2013 /Published online: 7 December 2013

(C) The Author(s) 2013. This article is published with open access at Springerlink.com

\begin{abstract}
A large female spider, Nephila jurassica, was described from Middle Jurassic strata of north-east China and placed in the modern genus Nephila (family Nephilidae) on the basis of many morphological similarities, but, as with many ancient fossils, the single specimen lacked synapomorphies of the family (Selden et al. 2011). In order to test the placement within the nephilid phylogenetic tree, Kuntner et al. (2013) calibrated the molecular phylogeny using $N$. jurassica in three different scenarios based on inferred mitochondrial substitution rates. They concluded that $N$. jurassica fitted better as a stem orbicularian than a nephilid. Now, a giant male spider has been discovered at the same locality that yielded $N$. jurassica. The two sexes are considered conspecific based on their similar morphological features, size, and provenance. The male cannot be accommodated in Nephilidae because of its pedipalp morphology, so the new genus Mongolarachne and family Mongolarachnidae are erected for the species. Comparison with possibly related families show that Mongolarachnidae is most likely on the orbicularian stem, close to other cribellate orbicularians (e.g.,
\end{abstract}

Communicated by: Sven Thatje

Electronic supplementary material The online version of this article (doi:10.1007/s00114-013-1121-7) contains supplementary material, which is available to authorized users.

P. A. Selden • C. Shih • D. Ren

College of Life Sciences, Capital Normal University,

Beijing 100048, China

D. Ren

e-mail: rendong@mail.cnu.edu.cn

P. A. Selden $(\bowtie)$

Paleontological Institute and Department of Geology, University of

Kansas, Lawrence, KS 66045, USA

e-mail: selden@ku.edu

URL: www.paulselden.net

P. A. Selden

Natural History Museum, London SW7 5BD, UK
Deinopoidea), which suggests a greater diversity of cribellate orbicularians during the Middle Jurassic.

Keywords Araneae $\cdot$ Chelicerata $\cdot$ Deinopoidea . Hypochiloidea $\cdot$ Mesozoic $\cdot$ Orbiculariae

\section{Introduction}

Palaeontology is littered with examples of fossils whose original interpretations have been overturned (in some cases literally) by the discovery of material which provides new evidence that was missing from earlier finds. Examples include the Cretaceous Oviraptor (Osborn, 1924), originally named for being an egg-stealer and later found to be a brooding theropod; Hallucigenia Conway Morris, 1977, described as a bizarre, stilting problematicum, was later shown to be an armoured onychophoran; and (closer to the taxon under discussion herein) Attercopus fimbriunguis (Shear, Selden and Rolfe, 1987), was first placed tentatively into the trigonotarbid arachnids (Shear et al. 1987), then redescribed as the oldest spider (Selden et al. 1991), and now forms the type of an extinct order of arachnids: Uraraneida Selden and Shear, 2008 (Selden et al. 2008). Normally, the new evidence comes many years later, but here we describe the male of a fossil spider species, first described only from the female, which came to light shortly after the original publication.

Nephila jurassica is a fossil spider which was described from a single, large, female specimen from the Jurassic of Daohugou, Inner Mongolia, China (Selden et al. 2011). It was placed in the modern genus Nephila on account of its large size and an assemblage of morphological features typical of that genus. The occurrence of a modern genus in strata as old as Jurassic seemed surprising, so Kuntner et al. (2013) tested three possible scenarios of calibration of molecular trees using this (and other) fossil data points. They concluded that $N$. jurassica is neither a Nephila nor a nephilid, but possibly a stem orbicularian. Here, we report the discovery of a giant 
male spider from the same locality, which we interpret as the male of $N$. jurassica. The distinctive palp, quite unlike modern nephilid palps, the plumose setal structure, and the presence of a calamistrum indicate that the species does not belong in Nephilidae, as predicted by Kuntner et al. (2013). We erect a new genus, Mongolarachne gen. nov., and new family, Mongolarachnidae fam. nov., to accommodate the species.

Comparison of the morphological features of Mongolarachne jurassica with potential modern relatives (Table 1) shows that certain features of the spider are found in the primitive hypochiloids, whilst others resemble those of cribellate orbicularians, such as the Deinopoidea. For example, study of both male and female specimens using a scanning electron microscope (SEM) reveals a plumose setal structure. It should be noted that that these are the first published SEM photographs of a non-amber fossil spider; the only previous publication of SEM photographs of a fossil spider was a preliminary report in 1976 of the use of SEM on a Baltic amber specimen (Mierzejewski 1976). We also submitted the type and only known specimen of the supposed araneoid Juraraneus rasnitsyni Eskov, 1984 from the Jurassic of Transbaikalia to SEM study. A recent restudy of this specimen showed that it is cribellate (Selden 2012), and the new SEM investigation reveals it has plumose setae, but different from those of Mongolorachne (see Electronic supplementary material Fig. 1). This is concordant with the results of Kuntner et al. (2013), who suggested it as a stem orbicularian.

We conclude that the new family Mongolarachnidae and the Juraraneidae are likely stem orbicularians and that there was a greater diversity of cribellate orbicularians in the Middle Jurassic than today.

\section{Materials and methods}

The specimens come from finely laminated, pale grey tuff near Daohugou Village, Wuhua Township, Ningcheng County, Inner Mongolia, China ( $41^{\circ} 19.532^{\prime} \mathrm{N}, 119^{\circ} 14.589^{\prime}$ E). The Daohugou beds were deposited in lacustrine conditions in a volcanic region (Ren et al. 2002) and are well known as a Fossil-Lagerstätte bearing plants, insects, crustaceans, arachnids, molluscs, amphibians, reptiles, and mammals. A Middle Jurassic age for the Daohugou biota has been proposed based on the composition of the insect fauna (Ren et al. 2002; Huang et al. 2006), conchostracans (Shen et al. 2003), and isotopic dating (Chen et al. 2004; Liu et al. 2004). The material is deposited in the College of Life Sciences, Capital Normal University, Beijing.

The specimens were studied and photographed under $70 \%$ ethanol using a Leica MZ16 stereomicroscope, and photographed using a Canon EOS 5D MkIII digital camera attached to the microscope and DSLR Assistant software (www.kaasoft.com) on an Apple MacBook Pro computer (Figs. 1a, b; 2a-f; and 3a). Figure 2, panels g and h, were made on a Leo 1550 field-emission SEM; see Electronic supplementary material for details. Figure $3 \mathrm{c}$ was photographed on a Zeiss Sigma Variable Pressure Field Emission SEM. These are the first SEM photographs to be published of matrix-preserved fossil spiders (Selden and Penney 2010). Photographs were manipulated using Adobe Photoshop software, and final drawings were made from the photographs using Adobe Illustrator. All measurements are in millimeters and were made from the photographs using Photoshop's analysis tool.

Table 1 is a comparison chart of various characters visible on the fossils with those of possible relatives. The modern comparators were chosen because they show morphological similarities to the fossils. The morphological characters are discussed below, with their states as shown in Table 1 (coded as 0 for their state in Mongolarachne, ? = not known in the fossil, all unordered). The matrix in Table 1 was analyzed using Mesquite 2.75 (http://www.mesquiteproject.org) (for which Mongolarachne male and female were merged) as an aid to examining the possible relationships of the Mongolarachnidae).

\section{Morphological characters}

Femoral trichobothria are absent in all taxa compared, including Mongolarachne, except that they occur on one or more femora in uloborids (Griswold et al. 2005; Opell 1979) and many tetragnathids (Álvarez-Padilla and Hormiga 2011). All taxa have short tibial trichobothria, but only in Mongolarachne and Nephilidae do these form a large cluster; in others, they are in one or two rows. Femoral trichobothria: 0 absent, 1 present; tibial trichobothria: 0 cluster, 1 present, 2 one row, 3 two rows.

Brushes of long setae on the ends of the tibiae (gaiters) occur only in female Nephilidae (legs 1, 2, and 4), Mongolarachne (all legs), Uloborus (leg 1), and the tetragnathid Opadometa (leg 4) (Table 1), although setal brushes also occur on leg 1 of many male spiders for signalling to mates (e.g., Framenau and Hebets 2007, Miller et al. 2012). Tibial gaiters: 0 present, 1 absent.

The third leg is very short $(<0.5 \times$ length of leg 1$)$ in Orbiculariae and in Mongolarachne; in other web spiders, it is also usually the shortest, but less so $(>0.5 \times$ length of leg 1$)$ (measurements from specimens and the following literature: Kraus 1956; Gertsch 1958; Hoffman 1963; Catley 1994; Gray 1994; Harvey 1995; Ramírez and Grismado 1997; Opell 1983; Yin et al. 2002; Penney 2003; Chang and Tso 2004; Joseph and Framenau 2012). Third leg: 0 short, 1 long.

Definitions of cuticular hair types follow Lehtinen (1967, Figs. 8-10) and Griswold et al. (2005, Figs. 147-148) (contra Comstock 1912; Green 1970; Cushing 2005), viz.: plumose 


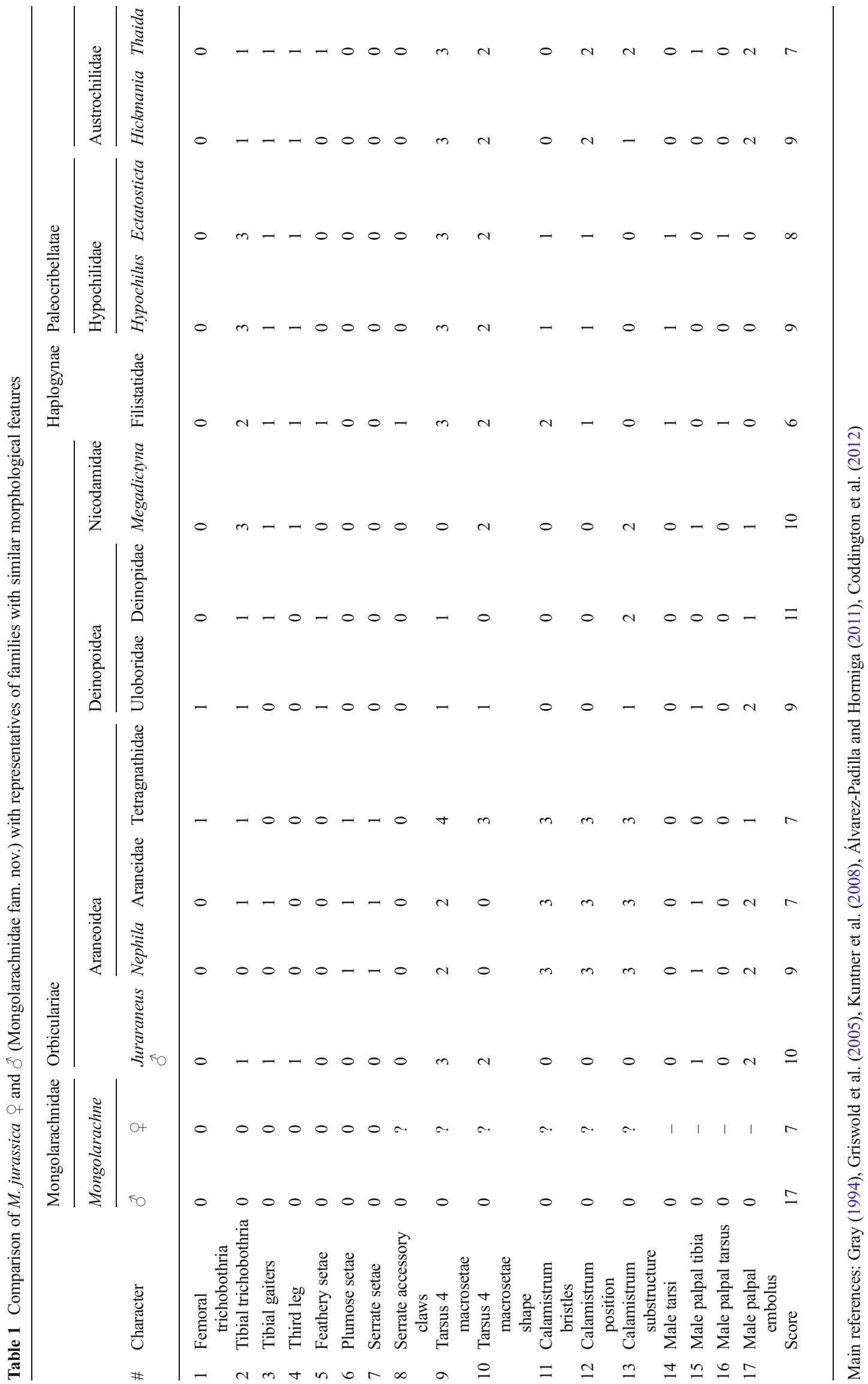


Fig. 1 M. jurassica: a allotopotype male CNU-ARANN2011001-1 (ð) and holotype female CNU-ARA-NN2010008 (†) specimens compared; b allotopotype male part; for explanation see (c). c Allotopotype male part, explanatory drawing of (b). Abbreviations: 1, 2, 3, 4, leg numbers; $c a$, calamistrum; $c h$, chelicera; $c r$, cribellar area; $c x$, coxa; $f$, fovea; $f e$, femur; $l b$, labium; $m t$, metatarsus; $m x$, maxilla; $o p$, opisthosoma; $p a$, patella; $P d$, pedipalp; $s t$, sternum; $t a$, tarsus; $t i$, tibia; $t r$, trochanter. Photographs a dry, $\mathbf{b}$ under polarized light with specimen under $70 \%$ ethanol; scale bars $=5 \mathrm{~mm}$
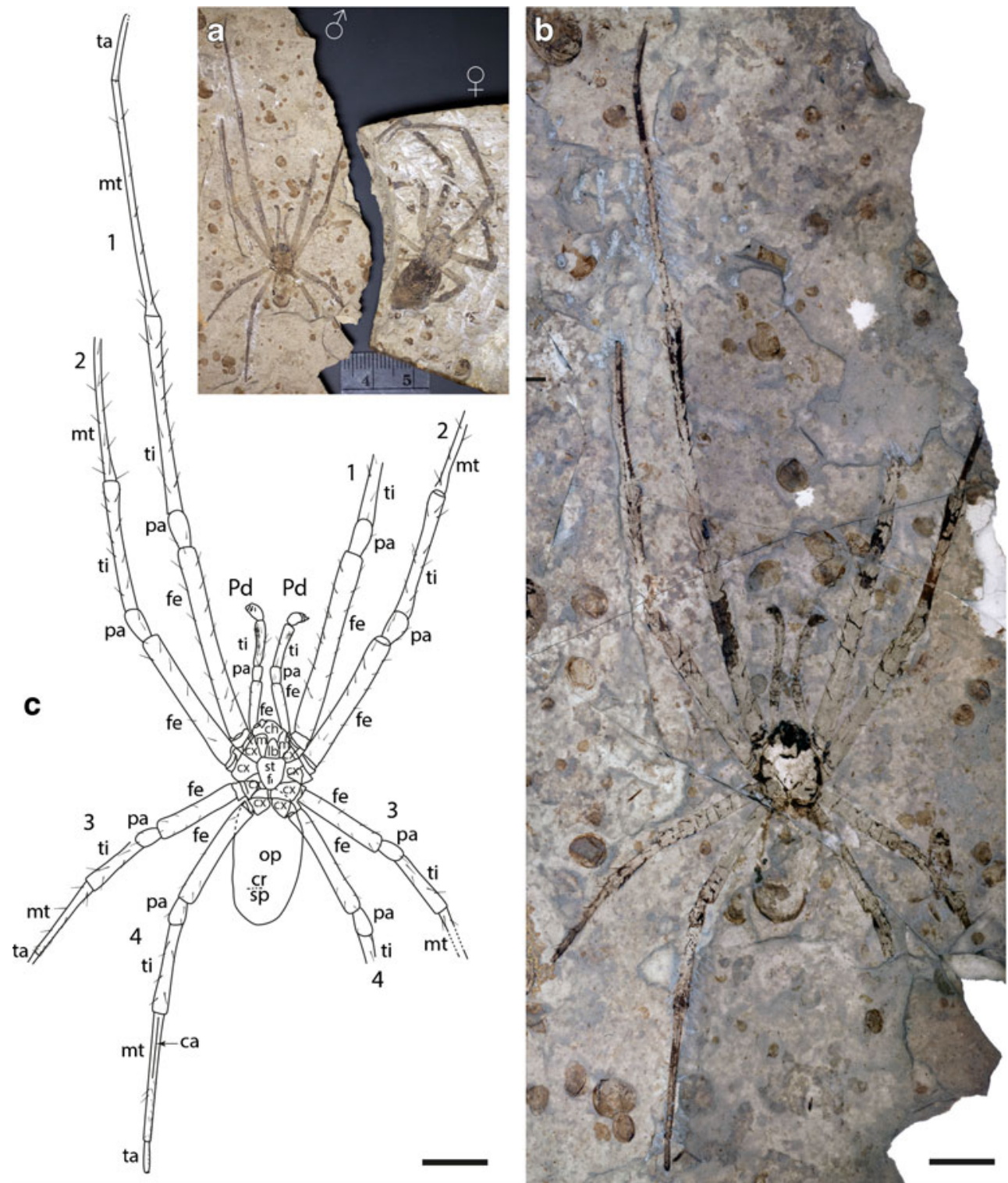

setae are normal body setae which bear abundant fine projections, generally in lines or whorls, over their entire surface; in some spiders, these are coarse and visibly different from simple setae with the naked eye (e.g., Dictynidae) while, in others, the fine projections are visible only under very high magnification (e.g., SEM). The latter is the kind of plumose seta found in the fossil specimens. Feathery setae are dendritic, with lateral branches resembling the veins in a leaf, which normally lie flat on the cuticle surface (e.g., Agelenidae: Bolzern et al. 2013, Fig. 2a). Simple and serrate setae are normal, fine, body setae found in Araneoidea; the former are smooth while the latter bear sparse, minute projections (Griswold et al. 2005). Plumose setae are present in all taxa compared except araneoids. Feathery setae have not been observed in Mongolarachne, despite extensive searches in both light and scanning electron microscopy. Feathery setae:
0 absent, 1 present; plumose setae: 0 present, 1 absent; serrate setae: 0 absent, 1 present.

Some spiders bear serrate accessory setae (=serrated bristles or false claws) adjacent to the median tarsal claw; these appear as gently s-shaped macrosetae (from which they are presumably derived) with ventral thorns. They function in conjunction with the median claw in manipulating silk on the web (Foelix 1970) and are characteristic of web-living spiders. In their Atlas of Entelegynae, Griswold et al. (2005) distinguished between these and sinuous plumose setae, seen, for example, in Phyxelida and Filistata (Griswold et al. 2005, Figs. 132C and 136C, respectively) which presumably have a similar function. However, they scored the Hypochilidae as lacking serrate accessory setae, yet they do occur in both Hypochilus and Ectatosticta (Electronic supplementary material, Fig. 3a-d, f). The serrate accessory claws of 

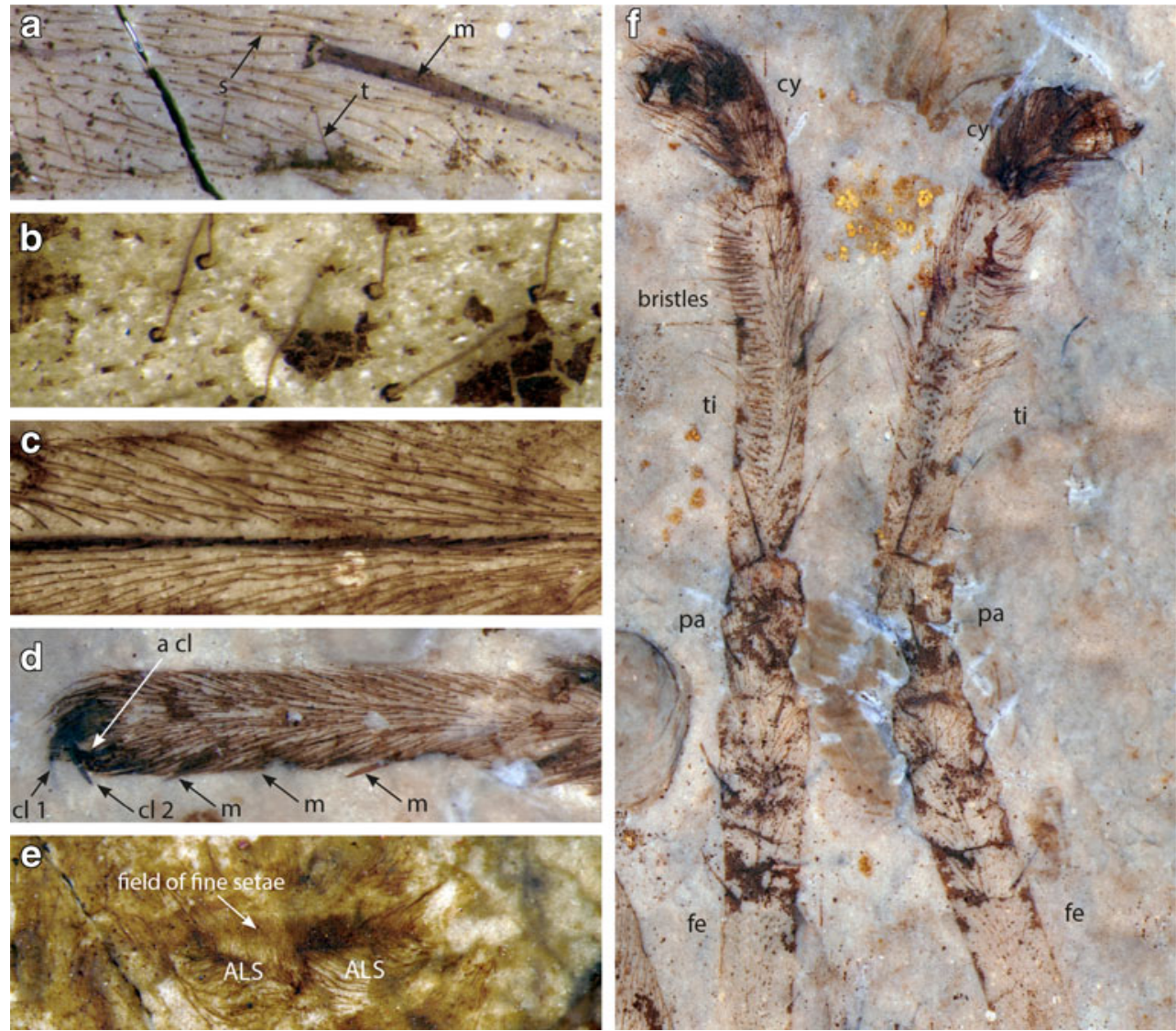

Fig. 2 M. jurassica, allotopotype male part CNU-ARA-NN2011001-1 (except e: counterpart CNU-ARA-NN2011001-2), morphological details; photomicrographs taken in polarized light with specimen under $70 \%$ ethanol: a Right leg 1 tibia showing cuticular structures: $m$, macroseta; $s$, seta; $t$, trichobothrium; $b$ higher magnification of trichobothria of left leg 4 , showing crescentic bothrial base; distal to the right; $\mathbf{c}$ basal part of left leg 4 metatarsus showing detail of calamistrum and simple setae; distal to the

left; $\mathbf{d}$ tarsus of left leg 4, showing one of the paired claws (cl 1), another claw ( $\mathrm{cl} \mathrm{2)}$ which could be the median claw or the second paired claw, accessory claws (S-shaped serrated setae, one shown at a cl), and row of distinctive, sustentaculum-like macrosetae $(m)$; distal to the left; e spinneret region of counterpart specimen, showing wide, oval field of fine setae anterior to anterior lateral spinnerets $(A L S) ; \mathbf{f}$ pedipalps showing elongated tibiae with longitudinal field of bristles

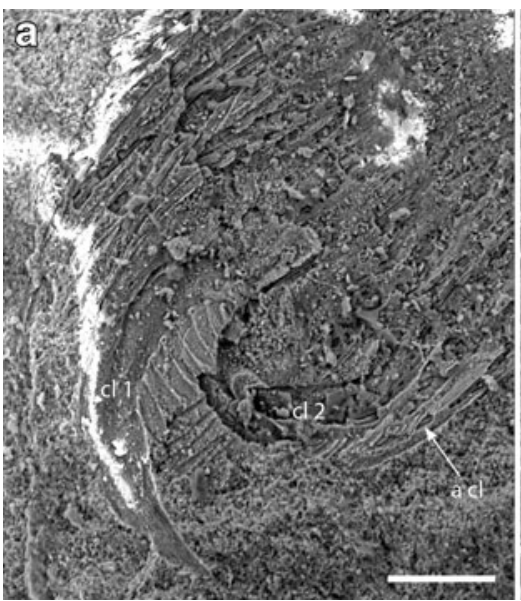

Fig. 3 M. jurassica, allotopotype male part CNU-ARA-NN2011001-1, SEM photographs: a tip of tarsus 4 (compare with Fig. 2d); paired claw (cl 1) showing seven blade-like pectines, possible median claw ( $\mathrm{cl} 2$ ), and serrate accessory claw (a cl); scale bar $=100 \mu \mathrm{m}$; b distal part of macroseta of tarsus 4 (left macroseta in (Fig. 2d)) showing curved tip,

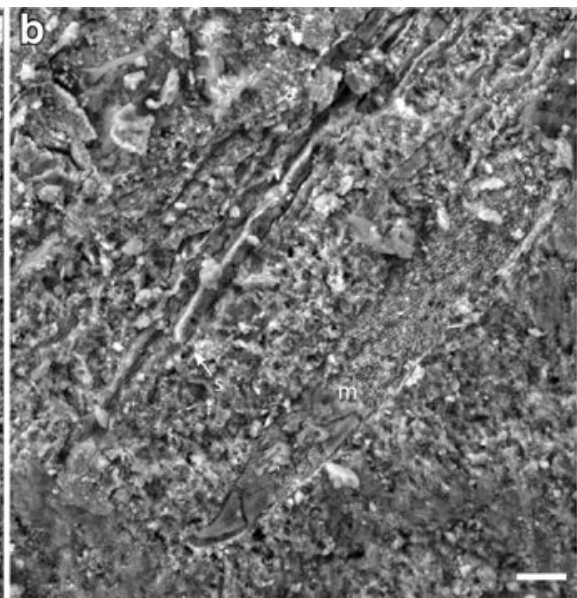

and numerous setae (one shown at $s$ ); note that both macroseta and setae have an infill of smooth, translucent (crystalline?) material (below $m$, extending to tip; above $s$ arrow), but where this is broken away, the external surface (above m; left of s arrow) shows a distinctive linear or spiral pattern of short barbs (cf. Lehtinen 1967, Fig. 8); scale bar $=20 \mu \mathrm{m}$ 
Mongolarachne (Figs. 2d and 3a) resemble those of Deinopis (Griswold et al. 2005, Fig. 135E). Serrate accessory claws: 0 present, 1 absent.

The sustentaculum is a distinctive macroseta on the ventral side of the distal end of tarsus 4 adjacent to the serrated bristles in Araneidae (Scharff and Coddington 1997; Griswold et al. 1998; Álvarez-Padilla and Hormiga 2011), and a line of such macrosetae on the fourth metatarsus and tarsus has also been mentioned for some araneid genera (Álvarez-Padilla and Hormiga 2011). Supposed sustentaculum-like macrosetae have been described in Nephilidae (Kuntner 2005, 2006) and Synotaxidae (Agnarsson 2003), but in these cases the shape of the macroseta is quite different from those of araneids, although it is in the same position on the tarsus. A row of sustentaculumlike macrosetae occurs on metatarsus-tarsus 4 of Mongolarachne, which is similar to the comb of similarly shaped macrosetae in Deinopidae (Griswold et al. 2005, Fig. 141B; Coddington et al. 2012, Fig. 5f), although these macrosetae are weakly organized in Menneus (Griswold et al. 2005). In contrast, the macrosetae in the uloborid comb are short and sculptured (Opell 1979, plate 1A, C). In Nicodamidae, Megadictyna has sustentaculum-like macrosetae uniformly distributed, while in Nicodamus similar macrosetae are not arranged in a comb (Griswold et al. 2005). Some other araneoids have macrosetae on the fourth tarsus, but these are not sustentaculum-like (Griswold et al. 2005). Among the taxa bearing sustentaculum-like macrosetae, there seems to be a variation from those arranged in a loose row (Mongolarachne, Nicodamus), through those in a distinct comb (Megadictyna, Deinopis), to the single sustentaculum (araneids, nephilids), which is likely derived with respect to the others (Griswold et al. 2005; Kuntner et al. 2008). The reduction of the row or comb could be related to the loss of the cribellum and calamistrum. Tarsus 4 macrosetae: 0 row, 1 comb, 2 sustentaculum, 3 one or more, 4 absent; tarsus 4 macrosetae shape: 0 sustentaculum-like, 1 sculptured, 2 simple, 3 absent.

The calamistrum varies in number of rows of bristles, length, position on the metatarsus, and whether is it situated on a pinched ridge or a shallow depression. The calamistrum is situated in an excavation of the metatarsus in Uloboridae (Opell 2001, Fig. 2; Griswold et al. 2005, Figs. 142E and 145A) and adjacent to an excavation in Hickmania (Gertsch 1958, Fig. 44); it is on a ridge in Deinopidae (Peters 1992, Fig. 8d) and Megadictyna, and adjacent to a ridge in Thaida (Griswold et al. 2005, Fig. 144A) (also pers. obs. for all). Calamistrum bristles: 0 uniseriate, 1 biseriate, 2 triseriate, 3 absent; calamistrum position: 0 proximal $1 / 2,1$ proximal $1 / 4,2$ medial, 3 absent; calamistrum substructure: 0 none, 1 excavation, 2 ridge, 3 absent. The associated cribellum is poorly preserved, but the spinneret region is visible in the counterpart (Fig. 2e, Electronic supplementary material Fig. 2c). A wide, oval field of fine setae in front of the anterior lateral spinnerets (which are both rotated to the right) resembles a similar patch of fine setae in some other cribellates (e.g., Griswold et al. 2005, Fig. 103; Davies 1993, Figs. 2 and 3) and may represent a vestigial cribellar region.

The tarsi of males of Filistatidae are slightly sinuous (Electronic supplementary material Fig. 3j), and those of hypochilid males are curved (Electronic supplementary material Fig. 3a,d; Doran et al. 2001, Fig. 1d). Male tarsi: 0 straight, 1 curved or sinuous.

The elongate tibia of the male pedipalp of Mongolarachne is unusual in spiders but is similar to those of the primitive araneomorph family Hypochilidae (Forster et al. 1987; Lehtinen 1967, Figs. 14-16), some Tetragnathidae (ÁlvarezPadilla and Hormiga 2011), and the filistatids Filistata and Kukulcania, for example. However, in Ectatosticta , the tarsus is also greatly elongated and bears distinctive spines, whereas the pedipalp tarsus in Mongolarachne is very short, and the tibia of Ectatosticta does not bear the distinctive bristles seen in Mongolarachne (Fig. 2f). Elongation of the male pedipalp of the filistatid Kukulcania is mainly achieved by a long femur and tibia, as in Mongolarachne (Barrantes and Ramírez 2013). Elongate pedipalps occur sporadically in spider families outside of the comparators listed here, for example, in the mimetid Gelanor (Shear 1981), for individual functional reasons. The tarsus is a spoon-shaped cymbium in most spiders; even if elongated (as in Austrochilidae), it is not much longer than the sclerites which it accommodates and which are attached laterally. In Filistatidae and Ectatosticta, the palpal sclerites are located at the tip of an elongated tarsus. The embolus of Mongolarachne is spiral and very similar to that seen in Ectatosticta (Forster et al. 1987, Fig. 78). The embolus is elongate in Nephila and weakly spiral or planispiral in Tetragnathidae. The pedipalp organ in Deinopis is distinct, with tight planispiral coiling (Coddington et al. 2012). Male palpal tibia: 0 elongate, 1 short; male palpal tarsus: 0 cymbium, 1 long; male palpal embolus: 0 spiral, 1 planispiral, 2 not spiral.

\section{Systematic palaeontology}

\section{Order Araneae Clerck, 1757}

Suborder Opisthothelae Pocock, 1892

Infraorder Araneomorphae Smith, 1902

Family Mongolarachnidae fam. nov.

Etymology from the genus Mongolarachne gen. nov.

Diagnosis A family of araneomorph spiders distinguished by the following combination of characters: both sexes of large size; cribellate, with straight, uniseriate calamistrum occupying proximal half of fourth metatarsus; distal metatarsus and tarsus of fourth leg with row of sustentaculum-like macrosetae; finely plumose setae; lacking feathery setae; cluster of many trichobothria in proximal half of all tibiae. 
This family differs from Juraraneidae by the structure of the male palp; from Recent Araneoidea by the presence of plumose setae and a calamistrum in Mongolarachnidae; from Deinopoidea by the tibial trichobothria in a large cluster, lack of feathery setae, and the shape of the male palpal embolus in Mongolarachnidae; from Nicodamidae by the tibial trichobothria in a cluster, presence of tibial gaiters, short third leg, curved tip to tarsus 4 macrosetae, and male palpal structure in Mongolarachnidae; from Filistatidae by a cluster of tibial trichobothria, tibial gaiters, short third leg, lack of feathery setae, presence of serrate accessory claws, tarsus 4 macrosetae, calamistrum structure, and straight tarsi and palp structure in the male of Mongolarachnidae; and from Palaeocribellatae by the cluster of tibial trichobothria, tibial gaiters, short third leg, tarsus 4 macrosetae, and calamistrum position in Mongolarachnidae (see Table 1).

Type genus Mongolarachne gen. nov. The family is monotypic.

Etymology from the Inner Mongolia Autonomous Region, where the fossils were discovered, and the Greek $\alpha \rho \alpha \dot{\alpha} \chi \vee \eta$ (L. arachne), a spider.

Diagnosis: Tibial gaiters on leg 3 as well as on all other legs (weak in the adult male); male pedipalp extremely elongate, with especially long tibia bearing field of bristles along its length; female epigyne nose-shaped.

Type species $N$. jurassica Selden, Shih and Ren, 2011 (Figs. 1, 2, 3, and 4; Electronic supplementary material Fig. 2).

M. jurassica (Selden, Shih and Ren, 2011) comb. nov.

Diagnosis: As for the genus.

Holotype: A female CNU-ARA-NN2010008.

Other material: An allotopotype male CNU-ARANN2011001-1 (part) and CNU-ARA-NN20110001-2 (counterpart). Both specimens from the finely laminated, pale grey tuff near Daohugou Village, Wuhua Township, Ningcheng County, Inner Mongolia, China $\left(41^{\circ} 19.532^{\prime} \mathrm{N}\right.$, $\left.119^{\circ} 14.589^{\prime} \mathrm{E}\right)$.

Description of allotopotype male Adult male: cuticular structures: setae and macrosetae finely plumose (Fig. 2g, h), no feathery setae (Fig. 2a); short trichobothria in large cluster $(>30$, fewer on Pd) in basal half of all tibiae, bothria asymmetric: thicker, crescentic rim proximally which thins distally (Fig. 2b); finely plumose macrosetae (Fig. 2a) on all post-trochanteral podomeres, many and large on dorsal surfaces, except femora, where shorter, thinner, sparse on ventral surfaces, except metatarsus 3 which has dense macrosetation in distal half.

Carapace pyriform, curved lateral sides, tapering forwards, more rounded posterolaterally. Eyes poorly preserved. Labium tongue-shaped, straight posterior border, lateral sides curve to meet anteriorly, longer than wide. Sternum shieldshaped, scalloped laterally, pointed posteriorly but not produced between coxae 4. Chelicera short, not porrect, subtriangular in lateral aspect. Pedipalp with elongated femur
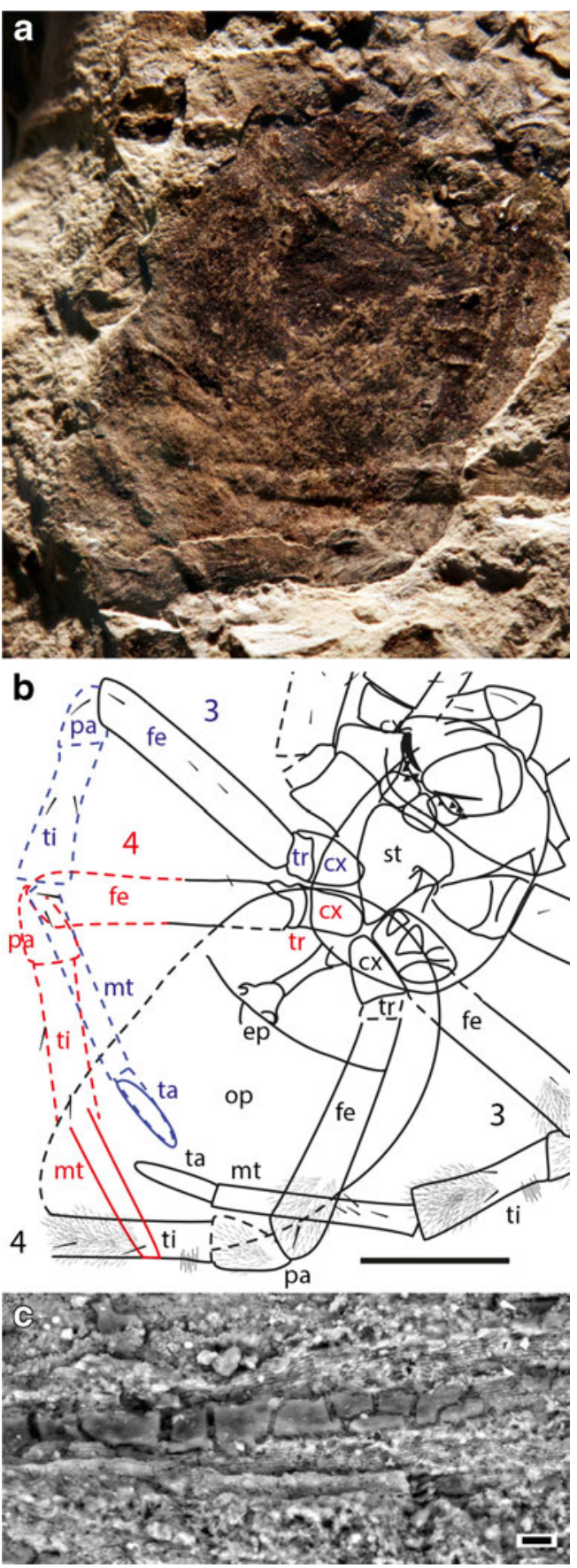

Fig. 4 M. jurassica, holotype female CNU-ARA-NN2010008 opisthosoma and posterior legs: a photograph in low-angle light of dry specimen; see $\mathbf{b}$ for explanation; $\mathbf{b}$ explanatory drawing of $\mathbf{a} ; 3$, 4, leg numbers; $c x$, coxa; $f e$, femur; $m t$, metatarsus; $o p$, opisthosoma; $p a$, patella; st, sternum; $t a$, tarsus; $t i$, tibia; $t r$, trochanter; blue and red show left legs 3 and 4, respectively, mirrored from preserved right legs; dashed lines are inferred morphology; scale bar $=5 \mathrm{~mm}$; c SEM photograph of numerous leg setae, showing infill of smooth, translucent (crystalline?) material, where broken away reveals external pattern of short barbs, as in the male; scale bar $=10 \mu \mathrm{m}$

and tibia (Fig. 2f); latter bearing conspicuous longitudinal field of bristles (short macrosetae), c. 3-wide, running from subproximal-ventral to lateral-distal; cymbium suboval, 
densely setose, especially ventrally and distally, with setae covering more distal palpal elements; other parts of pedipalp incompletely preserved, but suggestion of spiral element proximally, distal parts of embolus not preserved. Legs long, slender; leg formula 1243; weak gaiters on distal ends of tibiae 1-4; tarsus 4 (Fig. 2d) with 3 claws and accessory claws; distal $1 / 2$ of metatarsus and tarsus 4 with row of asymmetric macrosetae with slightly curved tips (resembling sustentacula) (Fig. 3b) ventrally; proximal $1 / 2$ of metatarsus 4 with calamistrum composed of straight, single row of bristles dorsally (Fig. 2c). Opisthosoma cylindrical with rounded anterior and posterior. Wide, oval field of fine setae (Fig. 2e; Electronic supplementary material Fig. 2c) situated c. 2/3 of length of opisthosoma from anterior, anterior lateral spinnerets posterior to this field, smaller posterior lateral spinnerets.

Measurements (millimeters): body length 16.54; carapace length 6.74 , width 5.05 ; opisthosoma length 10.86 , width 5.42 , length/width ratio 2.00 ; cribellar area width 1.97 ; sternum length 2.55 , width 2.31 , length/width ratio 1.10 ; labium length $1.58, \mathrm{~W} 1.18$, length/width ratio 1.34 ; maxilla length 1.77 , width 0.94 , length/width ratio 1.88 ; leg formula (longest to shortest): 1243; podomere lengths: pedipalp femur 4.05, patella 1.24 , tibia 3.79 , tarsus 1.68 , total (fe-ti) 9.08 , total (fe-ta) 10.76 ; leg 1 coxa 1.74 , trochanter 0.85 , femur 15.10 , patella 2.99 , tibia 15.96 , metatarsus 19.00 , tarsus $\geq 5.35$, total (fe-ti) 34.05, total (fe-ta) $\geq 58.16$; leg 2 coxa 1.84 , trochanter 0.69 , femur 11.46 patella 2.67 , tibia 10.43 , metatarsus $>11.53$, total (fe-ti) 24.56; leg 3 coxa 1.69, trochanter 0.54 , femur 6.76, patella 1.99 , tibia 5.56 , metatarsus 6.97 , total (fe-ti) 14.31; leg 4 coxa 1.83 , trochanter 0.57 , femur 9.13 , patella 2.21, tibia 7.39, metatarsus 10.38 , tarsus 2.64 , total (fe-ti) 18.73 , total (fe-ta) 31.68 .

Additions to interpretation of holotype female The original description (Selden et al. 2011) described the setae as simple, not plumose, which is how they appear under the light microscope. In this investigation, the specimen was studied under the SEM, which shows that the setae are, in fact, finely plumose (Fig. 4c).

The opisthosoma shows additional details when viewed under low-angle incident light (Fig. 4a, b). Along the midline about halfway between the opisthosoma and the posterior tip of the opisthosoma lies a wide, short, elliptical structure (width 2.95). Posterior to this structure, about halfway between it and the posterior end of the opisthosoma, lies a transverse ridge. Right leg 3 is seen to continue as a similar raised ridge across the posterior right side of the opisthosoma. By mirroring the preserved parts of legs 3 and 4 from the right side of the specimen onto the left (Fig. 4b), it can be seen that these structures most likely represent the distal parts of legs 3 and 4. These leg parts appear as raised ridges beneath the opisthosoma, yet the preserved parts of right leg 4 beyond the opisthosoma boundary lies on a level higher in the matrix than the opisthosoma, which at first seems incompatible with such an interpretation. However, if one considers that the carcass was buried in fine volcanic ash, which later became compressed, it is easy to envisage that a leg lying above the opisthosoma would prevent some compaction beneath and so imprint a ghost reflection of its shape as a raised ridge underneath.

\section{Discussion}

It is impossible to know for certain whether the giant male does, indeed, belong to the same species as the previously described female. The situation, however, is akin to the problem of matching sexes in museum collections of extant spiders which have been collected from the same locality but at different times: their co-occurrence in the same horizon and locality, and many similar morphological features, lead to the conclusion of conspecificity. Matching of males and females has proved possible in other geological situations, including the Daohugou beds (Selden and Huang 2010). The similar, large size of both sexes is a striking feature; generally, male spiders are somewhat smaller than females, and extremely so in the case of some Orbiculariae (Vollrath and Parker 1997), and are only very rarely larger (Schütz and Taborsky 2003). Despite several years of intensive fossil collecting at the Daohugou locality, no bigger spider has been discovered than Mongolarachne. Many morphological features are shared between the male and female that are not found in other species (mostly undescribed) from Daohugou. While many spiders bear trichobothria in one or two rows on the tibia (where they are commonly short: Forster and Gray 1979), the large cluster of tibial trichobothria found in both sexes of Mongolarachne is distinctive. The brushes of long setae (gaiters) occur on all legs in the female of Mongolarachne and are also found, though much more weakly, in the male. Other features, such as shorter femoral macrosetae, lack of trichobothria on other podomeres, and plumose setal structure are shared by both sexes.

Phylogenetic placement: The holotype female of Mongolarachne was originally placed in the family Nephilidae because features were consistent with the morphology of the extant members of this family, particularly Nephila (Selden et al. 2011). The combination of large size, gaiters on the legs, short femoral macrosetae, and lack of femoral trichobothria suggest this genus, although synapomorphies of Nephilidae (there are c. 15, of which about half are behavioral, the rest mostly genitalic: Hormiga et al. 1995) are not visible in the fossil. In contrast, the newly discovered adult male is so unlike modern Nephila that a re-evaluation of the placement of the genus is necessary.

It can be seen from the scores in Table 1 that Deinopidae shares the largest number of character states with Mongolarachne, followed by Juraraneus and Megadictyna. 
Purely out of interest, running Mesquite on the data in Table 1 resulted in 1,978 most-parsimonious trees with a tree length of 47. However, the goal of the present analysis was to try and determine how the fossil taxon relates to the comparators, rather than perform a fruitless phylogenetic analysis on few, disparate taxa and characters. So, a tree was constructed based on recent analyses (e.g., Blackledge et al. 2009; Dimitrov et al. 2012), and Mongolarachne was moved around the tree to find the position where the tree length was shortest. A single tree of length 52 (Fig. 5) places Mongolarachne as sister to the modern Orbiculariae. Placing Austrochilidae above Filistatidae in the tree (as suggested by some recent hypotheses: Griswold et al. 2005; Agnarsson et al. 2013) produced four trees of length 51 and one of 50 (Electronic supplementary material Fig. 4). The conclusion to be drawn from this analysis is that Mongolarachne lies somewhere near the base of the Orbiculariae, perhaps among the cribellate orbicularians, or the stem group to Orbiculariae.

A number of other factors suggest an orbicularian affinity rather than hypochiloid or filistatid. The third leg being particularly short is a feature shared by Mongolarachne and most orbicularians, but not the hypochiloids or filistatids. A median tarsal claw and the serrate accessory claws are characteristics of web spiders; ground spiders generally have two tarsal claws, rarely a median claw, commonly specialized claw tufts and/or scopulae, but not serrate accessory claws. The type of web woven by Mongolarachne is, of course, unknown; however, the long, thin legs and large body suggest a spider which hangs from a web, either a sheet or vertical web, rather than running on top of a sheet. Among web spiders, tibial gaiters are known only in orbweavers. Their function is poorly known, but crypsis has been suggested for those in Uloborus (Opell and Eberhard 1983). In Nephila, gaiters appear on legs 1, 2, and 4 in females at about the sixth instar, but some species lose them in adulthood (Robinson and Robinson 1973, 1976). Both males and females of Mongolarachne are large, and, while the male's legs are longer than those of the female, the traditional measurements of body size show the female to be somewhat larger than the male ( $+/ \delta$ body lengths $24.67 / 16.54$, ratio 1.49 ; $q / \hat{\sigma}$

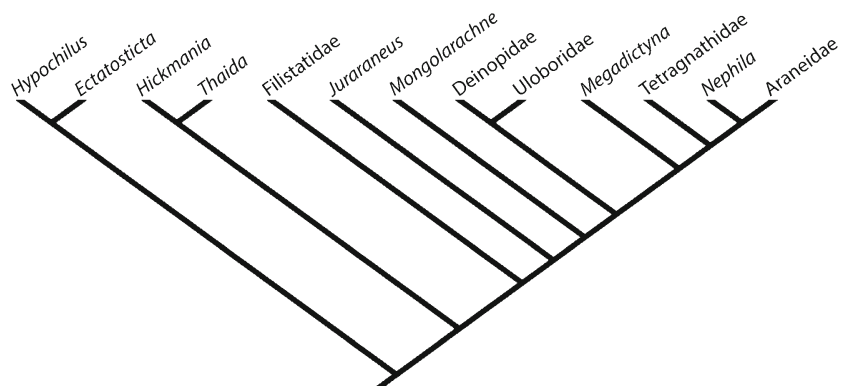

Fig. 5 Tree (length 52) derived from Table 1, with modern taxa constrained according to recent hypotheses (e.g., Blackledge et al. 2009; Dimitrov et al. 2012) carapace widths $6.83 / 5.05$, ratio 1.35 ; mean ratio 1.42 ). Among a variety of web spiders, this body size and dimorphism ratio compares closest with Deinopis (Deinopidae) and Eriophora (Araneidae) (Hormiga et al. 2000). Indeed, sexual size dimorphism is low in most orbicularians, but where extremes occur, e.g., in Cyrtophora and Argiope (Araneidae), and Nephilidae, the females are very large (Hormiga et al. 2000). The very long pedipalp in the Mongolarachne male, especially the elongation of the tibia, is striking. Long pedipalps occur in the males of large, sexually monomorphic spiders, and the unusual elongation of the tibia is especially pronounced in the long-legged hypochilids (Forster et al. 1987), and Kukulcania (Filistatidae) (Barrantes and Ramírez 2013), for example. Living hypochiloid spiders weave webs in dark, damp places: beneath rocky outcrops, among boulders, between tree buttresses and roots, in hollow $\operatorname{logs}$, and in caves (Forster et al. 1987). The chances of such a spider becoming trapped in an ash fall in a lake are remote, especially for the sedentary female. So, unless hypochiloids lived in different habitats in the Jurassic, Mongolarachne was more likely to have been a weaver of a web in an open habitat close to a lake margin, such as orbicularians today.

Fossil deinopoids (uloborids and deinopids) are known from Cretaceous strata (Dunlop et al. 2013) and undescribed forms also from the Jurassic (pers. obs.: Selden and Huang 2010). Araneoidea are characterized as ecribellate orbweavers, and the loss of the cribellate condition is considered to have occurred before the superfamily emerged within the Orbiculariae. J. rasnitsyni, a single adult male from the Middle Jurassic of Transbaikalia (Eskov 1984), was interpreted as an araneoid based on the complexity of the male pedipalp, with a large paracymbium, and the monotypic family Juraranidae was diagnosed on a unique combination of characters found in other araneoid families. Indeed, it has been suggested that Juraraneus could be accommodated in Araneidae (Wunderlich 1986). A restudy of the single specimen (Selden 2012) has revealed that it is cribellate, and SEM study (Electronic supplementary material Fig. 2) has shown that this specimen bears plumose setae, albeit different from those in Mongolarachne. It has been suggested by M. J. Roberts, (in lit.) that Juraraneus is a subadult male, and the structures within the palp are visible but yet to erupt.

\section{Conclusions}

This analysis of the new family Mongolarachnidae, in comparison with Juraraneidae and possible modern relatives, shows that the fossils appear to be related to the orbicularian Deinopidea, and possibly some Nicodamidae and Austrochilidae. This suggests that a greater diversity of cribellate orbicularians existed in the Mesozoic, some survivors of which occur at the present day. 
This first use of SEM as a technique for the study of fossil spiders has proved remarkably effective. Indeed, it should now be applied to other, possibly contentious, records of fossil spiders. However, in order to be really practical, it is necessary fully to appreciate the phylogenetic signals of setal ultrastructure among modern spider families. The importance of this was emphasized by Lehtinen $(1967,2013)$, investigated in a preliminary way by Green (1970), and mentioned by various authors in phylogenetic studies (e.g., Griswold et al. 2005). A new study along the lines of Green's master's thesis would be most desirable.

Acknowledgments PAS thanks Ingi Agnarsson, Jason Bond, Jason Dunlop, William Eberhard, Matjaž Kuntner, William Shear, and reviewers for comments and discussions; and David Moore (University of Kansas) and Max Hinman (Wichita State University) for their help in scanning electron microscopy. Darrell Ubick (California Academy of Sciences), Zack Falin (University of Kansas Museum of Natural History), and Jason Dunlop (Naturkundemuseum, Berlin) kindly supplied Recent material, and Alexander Rasnitsyn (Paleontological Institute, Russian Academy of Sciences) loaned the holotype of Juraraneus, for comparative study. This work was supported by an Alexander von Humboldt Foundation Research Award to PAS; and the National Basic Research Program of China (973 Program) (2012CB821906), the National Nature Science Foundation of China (Nos. 31230065, 41272006, 31071964), Project of Great Wall Scholar and KEY project of Beijing Municipal Commission of Education (grants KZ201310028033) the Scientific Research Key Program (KZ2010028005), and the China Geological Survey (12120111201161212011120115) to DR.

Open Access This article is distributed under the terms of the Creative Commons Attribution License which permits any use, distribution, and reproduction in any medium, provided the original author(s) and the source are credited.

\section{References}

Agnarsson I (2003) The phylogenetic placement and circumscription of the genus Synotaxus (Araneae: Synotaxidae), a new species from Guyana, and notes on theridioid phylogeny. Invert Syst 17:719-734. doi:10.1071/IS03002

Agnarsson I, Coddington JA, Kuntner M (2013) Systematics: progress in the study of spider diversity and evolution. In: Penney D (ed) Spider research in the 21 st century: trends \& perspectives. Siri Scientific Press, Manchester, pp 58-111

Álvarez-Padilla F, Hormiga G (2011) Morphological and phylogenetic atlas of the orb-weaving spider family Tetragnathidae (Araneae: Araneoidea). Zool J Linn Soc 162:713-879. doi:10.1111/j.10963642.2011.00692.x

Barrantes G, Ramírez MJ (2013) Courtship, egg sac construction, and maternal care in Kukulcania hibernalis, with information on the courtship of Misionella mendensis (Araneae, Filistatidae). Arachnology 16:72-80

Blackledge TA, Scharff N, Coddington JA et al (2009) Reconstructing web evolution and spider diversification in the molecular era. Proc Natl Acad Sci U S A 106:5229-5234

Bolzern A, Burckhardt D, Hänggi A (2013) Phylogeny and taxonomy of European funnel-web spiders of the Tegenaria-Malthonica complex (Araneae: Agelenidae) based upon morphological and molecular data. Zool J Linn Soc 168:723-848. doi:10.1111/zoj.12040
Catley KM (1994) Descriptions of new Hypochilus species from New Mexico and California: with a cladistic analysis of the Hypochilidae (Araneae). Am Mus Novit 3088:1-27

Chang Y-H, Tso I-M (2004) Six newly recorded spiders of the genera Araneus, Larinia, Eriophora, Thanatus, Portia and Dolichognatha (Araneae: Araneidae, Philodromidae, Salticidae and Tetragnathidae) from Taiwan. Acta Arachnol 53:27-33

Chen W, Ji Q, Liu D-Y, Zhang Y, Song B, Liu X (2004) Isotope geochronology of the fossil-bearing beds in the Daohugou area, Ningcheng, Inner Mongolia. Geol Bull China 23:1165-1169

Clerck C (1757) Aranei Svecici, descriptionibus et figuris æneis illustrati, ad genera subalterna redacti, speciebus ultra LX determinati. Salvii, Stockholm

Coddington JA, Kuntner M, Opell BD (2012) Systematics of the spider family Deinopidae with a revision of the genus Menneus. Smithson Contrib Zool 636:1-61

Comstock JH (1912) The spider book. Doubleday, Page and Co., Garden City, New York

Conway Morris S (1977) A new metazoan from the Cambrian Burgess Shale of British Columbia. Palaeontology 20:623-640

Cushing PE (2005) Introduction. In: Ubick D, Paquin P, Cushing PE, Roth VD (eds) Spiders of North America: an identification manual. American Arachnological Society, College Park, MD, pp 1-17

Davies VT (1993) The spinning field and stridulating apparatus of penultimate male Macrogradungula moonya (Araneae: Austrochilidae: Gradungulidae). Mem Queensland Music 33:175-178

Dimitrov D, Lopardo L, Giribet G, Arnedo MA, Álvarez-Padilla F, Hormiga G (2012) Tangled in a sparse spider web: single origin of orb weavers and their spinning work unravelled by denser taxonomic sampling. Proc R Soc B Biol Sci 279:1341-1350. doi:10.1098/ rspb.2011.2011

Doran NE, Richardson A, Swain R (2001) The reproductive behaviour of the Tasmanian cave spider Hickmania troglodytes (Araneae: Austrochilidae). J Zool 253:405-418

Dunlop JA, Penney D, Jekel D (2013) A summary list of fossil spiders and their relatives. http://research.amnh.org/entomology/spiders/ catalog/index.html. Accessed 18 October 2013

Eskov KY (1984) A new fossil spider family from the Jurassic of Transbaikalia (Araneae: Chelicerata). N Jb Geol Pal Mh 1984:645-653

Foelix RF (1970) Structure and function of tarsal sensilla in the spider Araneus diadematus. J Exp Zool 175:99-123

Forster RR, Gray MR (1979) Progradungula, a new cribellate genus of the spider family Gradungulidae (Araneae). Aust J Zool 27:1051-1071

Forster RR, Platnick NI, Gray MR (1987) A review of the spider superfamilies Hypochiloidea and Austrochiloidea (Araneae, Araneomorphae). Bull Am Mus Nat Hist 185:1-116

Framenau VW, Hebets EA (2007) A review of leg ornamentation in male wolf spiders, with the description of a new species from Australia, Artoria schizocoides (Araneae, Lycosidae). J Arachnol 35:89-101

Gertsch WJ (1958) The spider family Hypochilidae. Am Mus Novit 1912:1-28

Gray MR (1994) A review of the filistatid spiders (Araneae: Filistatidae) of Australia. Rec Aust Mus 461:39-61

Green LA (1970) Setal structure and spider phylogeny. Eastern Michigan University, Dissertation

Griswold CE, Coddington JA, Hormiga G, Scharff N (1998) Phylogeny of the orb-web building spiders (Araneae, Orbiculariae: Deinopoidea, Araneoidea). Zool J Linn Soc 123:1-99

Griswold CE, Ramírez MJ, Coddington JA, Platnick NI (2005) Atlas of phylogenetic data for entelegyne spiders (Araneae: Araneomorphae: Entelegynae) with comments on their phylogeny. Proc Calif Acad Sci 56:1-324, Supplement II

Harvey MS (1995) The systematics of the spider family Nicodamidae (Araneae: Amaurobioidea). Invertebr Taxon 9:279-386

Hoffman RL (1963) A second species of the spider genus Hypochilus from eastern North America. Am Mus Novit 2148:1-8 
Hormiga G, Eberhard WG, Coddington JA (1995) Web-construction behaviour in Australian Phonognatha and the phylogeny of nephiline and tetragnathid spiders (Araneae: Tetragnathidae). Aust J Zool 43:313-364

Hormiga G, Scharff N, Coddington JA (2000) The phylogenetic basis of sexual size dimorphism in orb-weaving spiders (Araneae, Orbiculariae). Syst Biol 49:435-462

Huang D-Y, Nel A, Shen Y-B, Selden P, Lin Q (2006) Discussions on the age of the Daohugou fauna - evidence from invertebrates. Prog Nat Sci 16:308-312

Joseph MM, Framenau VW (2012) Systematic review of a new orbweaving spider genus (Araneae: Araneidae), with special reference to the Australasian-Pacific and South-East Asian fauna. Zool J Linn Soc 166:279-341. doi:10.1111/j.1096-3642.2012.00845.x

Kraus O (1956) Eine neue Deinopide aus El Salvador (Arach., Araneae). Senckenberg Biol 37:167-170

Kuntner M (2005) A revision of Herennia (Araneae: Nephilidae: Nephilinae), the Australasian "coin spiders. Invertebr Syst 19:391436. doi:10.1071/IS05024

Kuntner M (2006) A monograph of Nephilengys, the pantropical "hermit spiders" (Araneae, Nephilidae, Nephilinae). Syst Ent 32:95-135. doi:10.1111/j.1365-3113.2006.00348.x

Kuntner M, Coddington JA, Hormiga G (2008) Phylogeny of extant nephilid orb-weaving spiders (Araneae, Nephilidae): testing morphological and ethological homologies. Cladistics 24:147-217. doi: 10.1111/j.1096-0031.2007.00176.x

Kuntner M, Arnedo MA, Trontelj P, Lokovšek T, Agnarsson I (2013) A molecular phylogeny of nephilid spiders: evolutionary history of a model lineage. Mol Phylogenet Evol 69:961-979. doi:10.1016/j. ympev.2013.06.008

Lehtinen PT (1967) Classification of the cribellate spiders and some allied families, with notes on the evolution of the suborder Araneomorpha. Ann Zool Fenn 4:199-468

Lehtinen PT (2013) Polyphyly of Orbiculariae, based on different ultrastructure of all chitinous structures and lacking homology of structures of the copulatory organs. In: Abstract book, 19th International Congress of Arachnology, Kenting National Park, Taiwan, June 2328, 2013. pp 91-92

Liu Y-Q, Liu Y-X, Li P-X, Zhang H, Zhang L-J, Li Y, Xia H-D (2004) Daohugou biota-bearing lithostratigraphic succession on the southeastern margin of the Ningcheng basin, Inner Mongolia, and its geochronology. Geol Bull China 23:1180-1185

Mierzejewski P (1976) Scanning electron microscope studies $n$ the fossilization of Baltic amber spiders (preliminary note). Ann Med Sect Pol Acad Sci 21:1-2

Miller JA, Griswold CE, Scharff N, Řezáč M, Szuts T, Marhabaie M (2012) The velvet spiders: an atlas of the Eresidae (Arachnida, Araneae). ZooKeys 195:1-144. doi:10.1038/nrc822

Opell BD (1979) Revision of the genera and tropical American species of the spider family Uloboridae. Bull Mus Comp Zool 148: 443-549

Opell BD (1983) Lubinella, a new genus of Uloboridae (Arachnida, Araneae). J Arachnol 11:441-446

Opell BD (2001) Cribellum and calamistrum ontogeny in the spider family Uloboridae: linking functionally related but separate silk spinning features. J Arachnol 29:220-226

Opell BD, Eberhard WG (1983) Resting postures of orb-weaving uloborid spiders (Araneae, Uloboridae). J Arachnol 11:369-376
Osborn HF (1924) Three new Theropoda, Protoceratops Zone, central Mongolia. Am Mus Novit 144:1-12

Penney D (2003) A new deinopoid spider from Cretaceous Lebanese amber. Acta Pal Pol 48:569-574

Peters HM (1992) On the spinning apparatus and the structure of the capture threads of Deinopis subrufus (Araneae, Deinopidae). Zoomorphology 112:27-37

Pocock RI (1892) XXXVIII.-Liphistius and its bearing upon the classification of spiders. Ann Mag Nat Hist 10(6):306-314

Ramírez MJ, Grismado CJ (1997) A review of the spider family Filistatidae in Argentina (Arachnida, Araneae), with a cladistic reanalysis of filistatid genera. Ent Scand 28:319-349

Ren D, Gao K-Q, Guo Z-G, Ji Q, Tan J-J, Song Z (2002) Stratigraphical division of the Jurassic in the Daohugou area, Nincheng, Inner Mongolia. Geol Bull China 21:584-591

Robinson MH, Robinson B (1973) Ecology and behavior of the giant wood spider Nephila maculata (Fabricius) in New Guinea. Smithson Contrib Zool 149:1-76

Robinson MH, Robinson B (1976) The ecology and behavior of Nephila maculata: a supplement. Smithson Contrib Zool 218:1-22

Scharff N, Coddington JA (1997) A phylogenetic analysis of the orbweaving spider family Araneidae (Arachnida, Araneae). Zool J Linn Soc 120:355-434

Schütz D, Taborsky M (2003) Adaptations to an aquatic life may be responsible for the reversed sexual size dimorphism in the water spider, Argyroneta aquatica. Evol Ecol Res 5:105-117

Selden PA (2012) A redescription of Juraraneus rasnitsyni Eskov 1984 (Araneae: Juraraneidae), from the Jurassic of Russia. Bull $\mathrm{Br}$ Arachnol Soc 15:315-321

Selden PA, Huang D (2010) The oldest haplogyne spider (Araneae: Plectreuridae), from the Middle Jurassic of China. Naturwissenschaften 97:449-459. doi:10.1007/s00114-010-0649-z

Selden PA, Penney D (2010) Fossil spiders. Biol Rev 85:171-206. doi: 10.1111/j.1469-185X.2009.00099.x

Selden PA, Shear WA (2008) Fossil evidence for the origin of spider spinnerets, and a proposed arachnid order. Proc Natl Acad Sci U S A 105:20781-20785

Selden PA, Shear WA, Bonamo PM (1991) A spider and other arachnids from the Devonian of New York, and reinterpretations of Devonian Araneae. Palaeontology 34:241-281

Selden PA, Shih CK, Ren D (2011) A golden orb-weaver spider (Araneae: Nephilidae: Nephila) from the Middle Jurassic of China. Biol Lett 7:775-778

Shear WA (1981) Structure of the male palpal organ in Mimetus, Ero, and Gelanor (Araneoidea, Mimetidae). Bull Am Mus Nat Hist 170:257262

Shear WA, Selden PA, Rolfe WDI, Bonamo PM, Grierson JD (1987) New terrestrial arachnids from the Devonian of Gilboa, New York (Arachnida, Trigonotarbida). Am Mus Novit 2901:1-74

Shen Y-B, Chen P-J, Huang D-Y (2003) Age of the fossil conchostracans from Daohugou of Ningcheng, Inner Mongolia. J Strat 27:311-313

Smith FP (1902) The spiders of Epping Forest. Essex Nat 12:181-201

Vollrath F, Parker GA (1997) Reply to Coddington et al. Nature 385:688

Wunderlich J (1986) Spinnenfauna gestern und heute. Erich Bauer bei Quelle \& Meyer, Wiesbaden

Yin CM, Griswold CE, Yan H-M (2002) A new ogre-faced spider (Deinopis) from the Gaoligong Mountains, Yunnan, China (Araneae, Deinopidae). J Arachnol 30:610-612 